\title{
MÉMORIA DE DOCENTES UNIVERSITÁRIOS: RESISTÊNCIA E LUTA NO CAMPUS UNIVERSITÁRIO DE ABAETETUBA
}

\author{
AVERAGE OF UNIVERSITY TEACHERS: \\ RESISTANCE AND FIGHT IN THE ABAETETUBA UNIVERSITY CAMPUS \\ Mara Rita Duarte de OLIVEIRA ${ }^{1}$ \\ Universidade da Integração Internacional da Lusofonia Afrobrasileira (UNILAB)
}

\begin{abstract}
Resumo: O presente artigo é parte de uma pesquisa mais ampliada sobre os docentes do Campus Universitário de Abaetetuba, que teve como objetivo apresentar os resultados da pesquisa intitulada Memória docente e narrativas de resistência na Universidade Federal do Pará, no período de 2013 a 2017, sendo parte da pesquisa financiada pelo PIBIC/UFPA e outra realizada sem financiamento. A pesquisa foi realizada com docentes do Campus Universitário de Abaetetuba, com o objetivo central de interpretar as estratégias e dispositivos de resistência docente aos modelos impositivos de instalação da Universidade heterônoma e neoprofissional, a partir da memória docente focalizando as narrativas dos docentes do Campus Universitário de Abaetetuba. Desse modo, verificamos que os docentes se baseiam na reflexão como forma de vivenciar e compreender a esfera do mundo da vida e do sistema, utilizando-se do trabalho intelectual como atividade de produção do conhecimento e na participação ativa na Universidade.
\end{abstract}

Palavras-chave: Memória. Resistência.

\begin{abstract}
This article is part of a broader research on the teachers of the Abaetetuba University Campus, which aimed to present the results of the research entitled Teaching memory and resistance narratives at the Federal University of Pará, from 2013 to 2017, part of the research financed by PIBIC / UFPA and another carried out without funding. The research was carried out with professors from the Abaetetuba University Campus, with the central objective of interpreting the strategies and devices of teacher resistance to the imposing models of installation of the heteronymous and neo professional University, from the teaching memory focusing on the narratives of the teachers of the Abaetetuba University Campus. Thus, we found that teachers are based on reflection as a way to experience and understand the sphere of the world of life and the system, using intellectual work as an activity of knowledge production and active participation in the University.
\end{abstract}

Keywords: Memory. Resistance. University

Universidade

\footnotetext{
${ }^{1}$ Doutora em Educação Brasileira pela Universidade Federal do Ceará (UFC). Mestre em Agriculturas Familiares e Desenvolvimento Sustentável pela Universidade Federal do Pará (2003). Professora Associada I da Universidade da Integração Internacional da Lusofonia Afrobrasileira (UNILAB). Professora do Programa de Pós-graduação Interdisciplinar em Humanidades (MIH/Unilab) Colaboradora do Programa de Pós-Graduação em Educação e Cultura (UFPA/Campus de Cametá). Coordenadora do Grupo de Estudos, Pesquisas e Extensão em Educação, Diversidade e Formação de Educadores Brasil/África (GEDIFE). Coordenadora de Rede de Formadores do Laboratório Virtual de Formação de professores (LABORVIR/Unilab). Colaboradora do Grupo de Estudos e Pesquisa: Memória, Formação Docente e Tecnologia (GEPEMe).). E-mail: mararita2213@gmail.com
} 


\section{INTRODUÇÃO}

A pesquisa "Memória docente e narrativas de resistência na Universidade" teve por objetivo registrar as memórias docentes dos docentes que atuam no Campus Universitário de Abaetetuba ${ }^{2}$, construindo as interpretações acerca do modelo universitário instalado na Universidade Contemporânea, essas interpretações poderão contribuir para o fortalecimento da compreensão do caráter de instituição social da Universidade.

Dessa forma, esse artigo é parte de uma pesquisa mais ampliada sobre os docentes do Campus Universitário de Abaetetuba, que teve como objetivo apresentar os resultados da pesquisa intitulada Memória docente e narrativas de resistência na Universidade Federal do Pará, no período de 2013 a 2017, sendo parte da pesquisa financiada pelo PIBIC/UFPA e outra realizada sem financiamento. A pesquisa foi realizada com docentes do Campus Universitário de Abaetetuba, com o objetivo central de interpretar as estratégias e dispositivos de resistência docente aos modelos impositivos de instalação da Universidade heterônoma e neoprofissional, na década de 2000, considerando as mudanças no governo e as alterações na carreira docente.

Nesse sentido no percurso da investigação mapeamos e interpretarmos as estratégias e dispositivos de resistência docente aos modelos impositivos da instalação da Universidade heterônoma e neoprofissional na realidade amazônica, através da rememoração da memória docente traduzida em narrativas de resistências dos docentes que atuam no campo da disputa políticaideológica de um projeto de Universidade democrática e autônoma, a partir das dos discurso de resistências e com elas que se estabelecem diálogos problematizadores, levando em consideração os contextos dos sujeitos e suas histórias, na tentativa de compreender as mudanças estruturais na Universidade contemporânea.

$\bar{S}$ ão entendidos teoricamente como narrativas, enunciados que explicitam sob outras formas os conflitos entre grupos subalternos e hegemônicos. Tais conflitos que expõem as estratégias de subordinação, assim como aquelas de resistências - ou seja, as disputas políticas, que constituem os enquadramentos sócio-históricos de um tipo de arena que configura uma economia política e simbólica da cultura universitária.

Assim, o poder de rememorar é uma forma catártica de reconciliação com o passado e afirmação do presente. As memórias se entrecruzam lentamente, em um recorte chamado vida, história, formação. Elas se encontram e demarcam o seu lugar. Não são apenas as memórias de docentes do ensino superior, são vidas marcadas e demarcadas por trajetórias pessoais, políticas,

\footnotetext{
${ }^{2}$ Estive professora no Campus Universitário de Abaetetuba (UFPA) no período de 2009 a 2018.
} 
profissionais e acadêmicas, que agora são transcritas em teias sociais e poéticas, em experiências e falas entrecruzadas sobre a vida na Universidade.

Nesse sentido, relembrar a construção desse processo é importante para demarcar as diferentes visões acerca da universidade que permeia o cotidiano acadêmico. Nisso, diríamos que a tarefa de rememorar está associada ao resgate mais profundo de nossa crença na mudança, no novo e em uma sociedade mais fraterna, em que a Universidade tenha um papel decisivo em estabelecer novos paradigmas para a contemporaneidade.

Com essa preocupação compreender os modelos impositivos de instalação da Universidade heterônoma e neoprofissional, aponta-se como um dos pontos de partida o resgate da memória dos docentes do Campus de Abaetetuba. Fazer isso requer não apenas uma incursão na trajetória política e histórica dos docentes da Universidade Federal do Pará. Neste sentido, recuperar elementos históricos com o intuito de aprofundar as análises realizadas durante a pesquisa.

Falar e escrever sobre a memória docente do Campus Abaetetuba exige o resgate de outras memórias mais particulares, da resistência e silenciamento; “[...] escrever não é apenas um desabafo, é uma vivência que muda" (BARON, 2000, p. 57). Assim, deseja-se "[...] salientar que o ato de recordar como o de esquecer ocorre devido a manipulações que podem ser conscientes ou inconscientes, elaboradas na estrutura psicológica do sujeito afetado por fatores como afetividade, interesse, desejo, censura ou inibição" (SOUZA, 2003, p. 91). Nesse sentido, apresenta-se a memória docente coletiva do Campus, através de narrativas contínuas e descontínuas que compõem a história da UFPA em Abaetetuba.

É preciso considerar que:

[...] há uma relação entre Universidade e sociedade, mais ampla, mais profunda, que não se esgota no fornecimento de tecnologia ou no apoio de alguma espécie ao setor empresarial. E isso dizemos sem nenhum preconceito contra as empresas, que são fator indispensável para a vida econômica de um país. A questão é apenas que as relações entre academia e a sociedade são mais variadas, mais abrangentes, e a nosso ver deve centrar-se, acima de tudo, nos tópicos que dizem respeito à cidadania (RIBEIRO, apud SANTOS, 1999, p. 12).

As pequenas "transgressões" realizadas no interior da universidade são possibilidades concretas de construção de práticas educativas mais solidárias. Essas práticas reconhecem a complexidade da região e assumem compromissos com a população pauperizada e excluída, no sentido de buscar estratégias de superação da condição desumana as quais tem sido historicamente submetida parte do povo abaetetubense. 
Nesse sentido, relembrar a construção desse processo é importante para demarcar as diferentes visões acerca da universidade que permeiam o cotidiano acadêmico. Nisso, diríamos que a tarefa de rememorar está associada ao resgate mais profundo da crença na mudança, no novo e em uma sociedade mais fraterna, em que a Universidade tenha um papel decisivo em estabelecer novos paradigmas para a contemporaneidade.

Fomos encontrando na narrativa dos docentes um profundo sentimento de compromisso com uma Universidade vinculada ao interesse da comunidade local. Isso fortalece a nossa crença em processos formativos emancipatórios tendo a Universidade como espaço profícuo para esses processos e a luta docente como protagonistas das conquistas geradas no Campus Universitário de Abaetetuba.

\section{HISTÓRIA ORAL NA PESQUISA}

Nessa pesquisa entrevistamos 06 (seis) docentes dos cursos de licenciatura, Letras, Pedagogia e Matemática do Campus Universitário de Abaetetuba. A condução metodológica se sustentou a partir do registro do percurso acadêmico-profissional dos docentes a partir da compreensão da trajetória pessoal e profissional dos entrevistados no Campus, enfocando a participação ativa como estratégias de resistência e luta docente na universidade.

$\mathrm{Na}$ perspectiva de registrar das memórias dos entrevistados, sendo que está centrada nas narrativas orais, assim rememorar o passado é uma forma de mergulhar no recôndito das memórias, onde as lembranças emergem de acordo com a memória dos sujeitos, optamos pela metodologia da história oral.

[...] a história oral apenas pode ser empregada em pesquisas sobre temas contemporâneos, ocorridos em um passado não muito remoto, isto é, que a memória dos seres humanos alcance, para que se possa entrevistar pessoas que dele participaram, seja como atores, seja como testemunhas. É claro que, com o passar do tempo, as entrevistas assim produzidas poderão servir de fontes de consulta para pesquisas sobre temas não contemporâneos. (ALBERTI, 1989; p. 4).

A história oral relaciona-se diretamente ao testemunho do vivido, onde o indivíduo testemunha aquilo que viveu em um tempo passado, a ponto dessa memória não se perder no tempo, a memória individual está constituída e permeada por memória coletiva adquirida através do meio que o indivíduo está inserido, seja familiar ou social. Segundo Halbwachs (2004; p.85) "todas as memórias são coletivas obtidas mediante da interação dos homens", portanto ela é essencial, pois possibilita a constituição de uma identidade a partir do próprio individuo e dos outros. 
O uso da memória como dispositivo de resgate de lembranças que de alguma forma sabemos que existem, entretanto precisam ser compreendidas; assim "testemunho vivido será recorrente ao próprio indivíduo que vivenciou os fatos ocorridos" (HALBWACHS, 1990; p. 18).

A história oral nos apresenta cada particularidade e singularidade que são testemunhos e vivências que suscitam do sujeito e pelo sujeito que vivenciou, são fatos e acontecimentos que diz respeito aos indivíduos e são reconstituídos a partir da reminiscência, bem mais que um documento linear.

A partir da memória reconstituímos a oralidade, sendo assim, para além de narrar e relatar permitiu aos sujeitos resgatar e reviver fatos acontecidos há tempos remotos, possibilitando assim uma reflexão acerca do tempo vivido. Logo, ressaltamos a importância da pesquisa a partir do método da história oral, pois apesar de trabalhar com o campo subjetivo possibilita compreender com clareza os acontecimentos históricos ocorridos naquela realidade, analisando as formas de resistência e organização docente.

\section{MEMÓRIA COMO ELEMENTO FORMATIVO}

De acordo com a perspectiva de Bosi (1994) a memória é algo que se constrói no movimento de um diálogo entre presente e passado, um processo vivo e dinâmico onde os sujeitos e os grupos recriam o passado no tempo presente. Desse modo, a memória, por um lado, permite entrelaçar o passado ao presente, tendo em vista a organização do futuro, e, por outro, compreende as lembranças como formas de trabalho docente, de pensamento, percepções e práticas que gestam processos novos de concepções científicas. A memória pode ser entendida, basicamente, como criativa e criadora de novas práticas científicas inseridas na reconstrução engajada no passado, na leitura do presente e na prospecção para o futuro.

Assim, a memória ocupa lugares diferentes nos diversos planos e percursos, embora não possua o mesmo alcance, nem a mesma consistência, na medida em que vai sendo resgatada, pois atravessa espaços vazios, do mesmo modo condensados pelos sentimentos, pelas clivagens ideológicas e pelas relações políticas. A organização dos lugares da memória une-se em forma de malhas que se tecem como rede, com retas e transversais, formando ilhas ${ }^{3}$ à parte, entretanto,

\footnotetext{
${ }^{3}$ Termo usado por Halbwachs em seu livro: A memória coletiva (1990)
} 
passíveis de serem colocadas em comunicação e, uma vez desencadeadas, constroem uma continuidade capaz de fazer a realidade, a partir do resgate do passado.

Considerando a memória em sua função prospectiva e projetiva, torna-se possível estabelecer vínculos que instigam a relacioná-la ao conhecimento. Dessas combinações, analisamos que a memória reconstruída, a partir de interesses do presente, faz os movimentos constantes entre os elos do passado e do futuro. Tal dimensão apresentada tem seu eixo norteador na memória como estrutura histórica e sociológica que se relaciona em uma construção coletiva, de uma unidade particular para a universal, capaz de organizar o presente e esboçar o futuro, a partir do passado tomando como referência a vida em sociedade.

Halbwachs (1990) apresenta em seus estudos que a memória, por mais que pareça expressar experiências estritamente individuais, é constituída por estruturas sociais mais amplas que antecedem ao sujeito. Lima (1995) afirma que:

A memória parece ser constituída de duas condições: 1) conservação ou persistência de uma certa forma de conhecimento passado: esse momento é a retentiva; 2) a possibilidade de evocar, na ocorrência, o conhecimento passado e de torná-lo atual ou presente: que é propriamente a lembrança. (LIMA, 1995, p. 70).

Nesse sentido, a memória como elemento narrativo tem em sua especificidade a oralidade e a escrita marcada pelo tempo passado, entendido como um período anterior aos acontecimentos de que um indivíduo se lembra diretamente. A leitura da memória possibilita reflexões do passado deixado por muitos traços visíveis que se percebem na expressão dos rostos, no aspecto dos lugares, no modo de pensar, de sentir, de fazer, de ser, conservado e reproduzido dentro dos ambientes coletivos. Desse modo, os elementos constitutivos da memória coletiva mergulham nos meios sociais, através do contanto com um passado, mais ou menos distante, que se configura em um quadro dentro do qual são guardadas as lembranças vividas e apreendidas pela história.

Os espaços coletivos permitem, então, que a memória seja reestruturada a partir das imagens, que se relacionam e não permitem a existência do vazio absoluto, isto é, propiciam às regiões do passado complementar-se, evidenciando as marcas da reconstrução.

Para Bosi (2001), a memória como função do conhecimento organiza o passado e ordena o tempo com a narrativa da comunicação que visa não à transmissão do acontecido em si, mas à construção que transforma os fatos suscitados pelas palavras. 


\subsection{Memória e Universidade: Aspectos da pesquisa}

Os sujeitos que fizeram parte desta pesquisa são docentes das Faculdades de Educação e Ciências Sociais e Ciências da Linguagem do Campus de Abaetetuba que lecionam nos cursos de licenciatura plena em Pedagogia, Letras (habilitação em língua portuguesa) e Matemática, respectivamente; que mobilizam o enfrentamento das práticas e teorias capazes de promover o ensino e a produção do conhecimento.

A partir das análises das entrevistas dos docentes foi possível compreendermos a vida acadêmica e como o professor constrói sua identidade como docente no ensino superior, suas percepções acerca dos modelos universitários, sua necessidade de reconhecimento e valorização profissional.

A concepção de memória neste trabalho pesquisa foi tomada na dimensão de abordagem epistemológica que gesta uma construção teórica, inserida nos processos políticos, econômico e social das lembranças analisadas através das falas dos docentes, sendo que tais lembranças se organizam em marcas do passado, reinterpretadas no presente e fazem prospecções para o futuro.

Nesse sentido, essas memórias foram tomadas como fonte de análise de dados, uma vez que se sistematizam como conhecimento dos docentes de um registro do passado para ser reinterpretado pelo presente. Portanto, a questão central desta pesquisa consiste em compreender como as memórias permeiam toda a produção do conhecimento no Campus de Abaetetuba nas áreas de atuação dos docentes entrevistados.

Trata-se de experiências sobre formas diferenciadas de alfabetização ou sobre as relações em sala de aula, de estudos do meio, das experiências em laboratórios, do trabalho interdisciplinar... (...) o resgate da sua trajetória profissional, suas experiências vivenciais, aquisições intelectuais e a forma como estas influenciaram sua vida. (KENSKI, 1994, p. 46)

Os docentes entrevistados participavam ativamente da vida acadêmica do Campus, assumiam cargos administrativos e ocupavam os espaços público nos Conselhos e Colegiados. Alguns participavam do sindicato de docentes, outros não. Porém, todos participavam ativamente da vida política e acadêmica do Campus.

Ao serem entrevistados sobre a micropolítica da instituição, percebemos com mais clareza que os docentes compreendem e atuam diretamente nela; pois ela se fazia no cotidianos dos espaços colegiados do Campus, mais especificamente nos cursos e em seus colegiados, observamos que os docentes apresentam bastante domínio público, tanto da legislação acadêmica interna, quanto das 
resoluções acadêmicas que norteiam de um modo geral a vida acadêmica que são diretrizes do trabalho docente na UFPA.

A maioria dos docentes conhecia profundamente as resoluções e normas dos cursos de graduação que são apresentadas pela Próreitoria de Ensino e Graduação (PROEG) e geralmente são discutidas, ampliadas e reformuladas pelo fórum de coordenadores dos cursos de graduação. Por outro lado, nos campi do interior, ainda têm, um quadro reduzido de docentes efetivos, sem contar com a rotatividade de docentes que, insatisfeitos com as condições dadas, almejam alcançar sua transferência para a Capital. Mas, apesar disso, os entrevistados relataram vários processos de luta em busca de mais vagas de docentes para seus cursos. Além de assumirem várias disciplinas no semestre e acumularem cargos administrativos para não deixarem o Campus a deriva.

Além disso, a falta de recursos para a realização de pesquisas que fomentem a articulação com o ensino, se esforçam para concorrer a editais de fomento e participarem ativamente de programas de pós-graduação, desenvolverem pesquisa e extensão.

A gestão acadêmica é outra questão que se tem como referência para a compreensão da participação docente no Campus, relacionada com a autonomia e o poder instituído nos cursos através de seus colegiados. Nas narrativas dos docentes, encontramos uma significativa relação entre autonomia e participação, pois se eles se sentem envolvidos em seus projetos de curso e em seus colegiados, sua participação na vida acadêmica se torna mais efetiva.

A maioria dos docentes considera que as decisões internas dentro dos colegiados são tomadas de forma democrática e horizontal com a participação de todos. Podemos afirmar que a participação nos colegiados dos cursos se caracteriza de forma diferenciada em relação à gestão do Campus, pois os cursos têm apresentado em suas pequenas células de organização a gestão colegiada em que as decisões são tomadas coletivamente, de modo que as ações são de responsabilidade dos sujeitos envolvidos nas tomadas de decisão. Com a gestão colegiada tudo o que se refere à organização do trabalho pedagógico passa por inúmeras discussões. O projeto pedagógico e o currículo assumem o formato que é discutido pelos docentes.

De um modo geral, os docentes se sentem à vontade para participar, discordar e propor mudanças e atividades no processo de organização do trabalho pedagógico, em virtude da participação horizontal dentro da estrutura colegiada de cada curso e de construírem espaços de luta no Campus.

Por isso, a participação docente na vida acadêmica e nos processos institucionais sempre deve ser alvo de constantes reflexões para compreendermos o status da universidade e sua produção. Desta 
forma, destaca-se o esforço empreendido pelos docentes em participação de tudo que se relaciona ao Campus.

Essa participação amplia a gestão colegiada do curso e colabora para as decisões democráticas e dialógicas que se revertem em qualidade no processo pedagógico na sala de aula. A participação ativa requer primeiramente que tenhamos consciência da ação que praticamos ou estamos em certa medida sujeitos. Ao participar, colocamos em exercício nossa reflexão crítica e nossos interesses. Assim, a participação é um modo de manifestação da existência humana, um produto da conscientização humana (PENTEADO, 1991).

Em nossas análises, as questões pesquisadas sobre o trabalho docente no Campus de Marabá não estão desconectadas de tais lutas. Ao contrário, é necessário um momento de reencontro entre a luta cotidiana e à docência universitária, em um exercício dialógico e dialético e em um processo valorização do trabalho docente em todos os níveis de ensino. Para nós, tal defesa se constitui radicalmente como a defesa da educação pública e, em especial, de uma universidade pública, plural, democrática e emancipadora.

Nesta direção, é importante que reconheçamos na participação ativa e democrática no interior da universidade um espaço de resistência ao modelo historicamente instituído de poder-dominação (REZENDE, 1987). Assim, podemos observar a resistência e luta dos docentes, que apesar das dificuldades encontradas nas atividades acadêmicas e administrativas, continuam participando e buscando melhores condições de trabalho.

\section{CONSIDERAÇÕES FINAIS}

A pesquisa realizada agrupa memórias de docentes como partilha de lembranças que dialogam entre si e efetivam interpretações do passado, do presente e projeções para o futuro, sobre o trabalho docente na graduação, situando a construção social do conhecimento no cotidiano, na complexidade da realidade articulada com a criação científica.

Verificou-se que os docentes baseiam-se na reflexão como forma de vivenciar e compreender a esfera do mundo da vida e do sistema, utilizando-se do trabalho intelectual como atividade de produção do conhecimento e da ação comunicativa para compartilhar da mesma linguagem, em uma estrutura dinâmica suscetível de inovações que possibilita a transformação da experiência humana na ação individual e coletiva. 
A produção do conhecimento se faz, assim, a partir de discussões e reflexões do trabalho pedagógico, desenvolvendo temáticas específicas de cunho marxista; da construção de práticas coletivas, cooperativas, dialogais e interdisciplinares; com interpretações, análises e explicações para os conceitos e problemas enfrentados na investigação de elementos educacionais, fundamentado nas práticas sociais.

Assim, as memórias dos docentes evidenciam as categorias que propiciam a produção do conhecimento sobre a educação, contemplando um diálogo teórico de novos saberes e a dinâmica cotidiana dos sujeitos envolvidos nos espaços escolares, nas igrejas, nos bairros, nas famílias, nos movimentos musicais e outras instituições presentes nas práticas diárias educacionais.

Esta pesquisa mostrou que a memória do docente associada à produção do conhecimento e a luta pela Universidade implica uma relação entre o local e o global, considerando as demandas educacionais dos novos imperativos do capitalismo, que determinam novas metodologias para cientificização do trabalho docente e a fragilização da Universidade pública, democrática e plural.

A investigação destaca que a memória dos docentes pesquisados se torna atividade produtiva e apresenta como produto o conhecimento fundamentado em eixos norteadores da ação comunicativa, o que possibilita compartilhar uma linguagem dinâmica e suscetível de inovações para reviver as incompletudes da tessitura do saber.

Como observado, nas memórias registradas neste trabalho, as políticas educacionais se alocam nas instituições federais de ensino superior para o fomento de pesquisas científicas e tecnológicas mediante convênios, contratos, programas, projetos de cooperação, por órgãos e entidades públicas de qualquer nível de governo, bem como por organizações internacionais.

Essas ações evidenciam a competição no campo científico-acadêmico, em uma disputa acirrada entre docentes pelos recursos destinados à ciência e tecnologia, como também pela exigência do produtivismo engendrado pelas agências de fomento.

Conclui-se que a ênfase desta pesquisa consiste em associar a memória do docente à produção do conhecimento com o objetivo de pensar no desenvolvimento da invenção, da descoberta, da construção teórica, da divulgação de novos saberes, bem como possíveis soluções para problemas da realidade, compreendendo todas as contradições que incidem sobre o conhecimento.

\section{REFERÊNCIAS}

ALMEIDA, Jane Soares, de. Mulher e Educação: A paixão pelo impossível. São Paulo: Fundação editora da UNESP, 1998. 
ANDRÉ, Marli et al. Estado da arte da formação de docentes no Brasil. Educação \& Sociedade, n 68, p. 301-309, Dezembro, São Paulo: 1999.

BOSI, E. O tempo vivo da memória: ensaios de psicologia social. São Paulo: Ateliê Editorial, 2003a.

1994.

Memória e sociedade: Lembranças de velhos. 3. Ed. São Paulo: Companhia das Letras, - Memória: enraizar-se é um direito fundamental do ser humano. Dispositiva. v. 1 n.2, p.196-199, ago./dez.2012. Entrevista concedida a Mozahir Salomão Bruck.

Memória e sociedade - lembranças de velhos. 3ed. São Paulo: Cia das Letras, 1994.

BRANDÃO, V. M. A. T. Labirintos da memória: quem sou eu? São Paulo: Editora Paulus, 2008.

GIROUX, H. A. Os docentes como intelectuais: rumo a uma pedagogia crítica da aprendizagem. Porto Alegre: Artes Médicas, 1997.

HALBWACHS, M. A memória coletiva. São Paulo: Vértice, 1990 e 2006.

JOSSO, Marie-Christine. Experiências de Vida e Formação. São Paulo: Cortez, 2004.

KENSKI, Vani Moreira. Sobre o conceito de memória. In: FAZENDA, Ivani (org) A pesquisa em educação e as transformações do conhecimento. Campinas: Papirus, 1997.

LE GOFF, Jacques. História e memória. São Paulo: Editora UNICAMP, 1992.

NÓVOA, António (Org.) Vida de Docentes. Porto: Porto Ed., 1992.

PAULO, Freire. Educação e mudança. 30ª ed.; Rio de Janeiro: Paz e Terra, 2007.

PENTEADO, Silvia Ângela Teixeira. Identidade e poder na Universidade. São Paulo: Cortez; Santos, SP: Unisanta Editora, 1998. 
Participação na universidade: Retrato preto e branco. São Paulo. Editora Pioneira, 1991.

POLLAK, Michael. Memória e Identidade: Estudos Históricos. Rio de Janeiro, vol. 5 nº10, 1992, p. $200-212$

PORTELLI, Alessandro. "Tentando aprender um pouquinho. Algumas reflexões sobre a ética na História Oral”. Projeto História, n 15. São Paulo: Abril, 1997 a.

RICHARDSON, Roberto Jarry. Pesquisa social: métodos e técnicas. 3. ed. São Paulo: Atlas, 1999. P. 327.

SOUZA, Elizeu Clementino de. O conhecimento de si: estágio e narrativas de formação de docentes. Rio de Janeiro: DP\&A, 2006.

SOUZA, Elizeu Clementino de; MIGNOT, Ana Chrytina Venancio. Histórias de Vida e formação de docentes. Quartet. Rio de Janeiro. 2008

TARDIF, M. Saberes docentes e formação profissional. Petrópolis: Vozes, 2002

THOMPSON, Paul. A voz do passado. São Paulo: Paz e Terra, 1992. 